\title{
O EX-Jogador de futebol Arthur Friedenreich em Museus da Cidade de São Paulo
}

\author{
Bruno Abrahão \\ Departamento de Educação Física, Faculdade de Educação, Universidade Federal da Bahia, Brasil \\ Francisco Caldas \\ Programa de Pós-graduação em Educação, Faculdade de Educação, Universidade Federal da Bahia, Brasil
}

\author{
Antonio Soares
}

Programa de Pós-graduação em Educação, Universidade Federal do Rio de Janeiro, Brasil

\begin{abstract}
RESUMO
Arthur Friedenreich é um dos primeiros ídolos na memória do futebol brasileiro. No que diz respeito à escrita da história deste esporte no Brasil às voltas com os mecanismos da identidade nacional, qual leitura podemos fazer sobre a apresentação do seu principal personagem nas primeiras décadas do século XX? A fim de responder a esta pergunta, o objetivo deste artigo é analisar os escritos e as imagens sobre o ex-jogador Arthur Friedenreich em museus da cidade de São Paulo. Como fontes, utilizou-se o conteúdo de três exposições dessa cidade. Para a análise das imagens fotográficas, baseamo-nos em conceitos de sentido denotativo e conotativo presentes em uma imagem fotográfica e, para textualidades, em uma análise documental. Os resultados revelaram que estas exposições procuraram apresentar o ex-jogador como um dos heróis negros ou mulatos do futebol que, pela competência e mérito no jogo, contribuiu não só para a democratização da modalidade no país, mas também expressou a especificidade do "racismo à brasileira". Recorrentemente rememorado pelos museus que guardam a memória do futebol brasileiro, a biografia de Friedenreich chama a atenção para o sucesso do primeiro grande ídolo como orgulho étnico e nacional do país, ao mesmo tempo em que revela as ambiguidades da identificação racial no Brasil.
\end{abstract}

\section{PaLAVRAS-ChaVe}

Arthur Friedenreich; futebol; museu; memória

\section{EX-SOCCER PLAyER ARThur Friedenreich in Museums in the City of Sao Paulo}

\begin{abstract}
Arthur Friedenreich is one of the first football Brazilian idols to become engraved in the memory of this sport. Regarding the writing of the history of this sport in Brazil dealing with the mechanisms of national identity, what can we learn with its main character in the first decades of the 2oth century? To answer this question, we deal with the writings and images of the former player Arthur Friedenreich in three exhibitions in museums, which are located in the city of Sao Paulo. In the study, we refer to photographic images as a concept of denotative and connotative meaning and textuality as documentary analysis. The results revealed that these exhibitions sought to present the former player not only as one of the biggest black (or mulatto) heroes of football due to his competence and merit in this field, but also contributed to the democratization
\end{abstract}


of the sport in the country. Besides, the research expressed the specificity of "the Brazilian way of racism". The prodigious performance of Friedenreich has been recurrently recalled by the museums that hold the memory of football. His biography draws attention to the success of the idol presenting the ambiguities of racial identification in Brazil.

\section{KEYWORDS}

Arthur Friedenreich; soccer; museum; memory

\section{INTRODUÇÃO}

Os museus e as exposições são guardiões da memória coletiva, que faz lembrar os elementos necessários para a construção imaginária ${ }^{1}$ das identidades nacionais. Por meio deles, podemos captar projetos ideológicos presentes nos mecanismos intencionais de lembrar e de esquecer. Nora (1993) chama a estes de "lugares de memória", uma vez que neles se destacam as referências aos mitos fundadores da construção das identidades. Têm como características o fato de ser material, funcional e simbólico; isto é, nos museus, em fotos e documentos escritos, observa-se materialmente aquilo que os curadores da esfera pública ou privada pretendem deixar para ser lembrado, com a função simbólica de enfatizar os elementos necessários para a construção das diferenças entre grupos e nações.

Nos dias atuais, os museus compõem uma sociedade que traz em suas tramas a pluralidade e a contradição, representações diversas e identidades conflitantes, rompendo com sua perspectiva de "relíquias do passado e guardião da verdade", que prevaleceu no século XIX. Dessa forma, o museu é um lugar que

seleciona os vestígios do passado, organizando discursos para promover e veicular suas representações sobre o pretérito, o presente e o que deverá permanecer para o devir (...). Ele é produtor e divulgador de sentidos na sociedade, se constituindo como uma instituição política, que pode se tornar veículo de cidadania. O museu não é uma estrutura estática, é um processo dinâmico, um espaço discursivo e interpretativo em permanente relação com os atores sociais. (Andreoni, 2011, p. 168)

A respeito das mudanças operadas no fazer museológico no século $X X$, os estudos de Azevedo e Alfonsi (2010) revelam que, a partir dos anos de 1970, ocorreram mudanças nas concepções sobre o que seria patrimônio e qual o papel de um museu. Assim, segundo os autores, "a ênfase quase exclusiva nas ações de conservação e documentação desloca-se, abrindo espaço para discussões a respeito das funções sociais de

\footnotetext{
'Benedict Anderson (1983), segundo Woodward (2000) desenvolveu o conceito de "comunidade imaginada". A identidade nacional não é inteiramente dependente da ideia que fazemos dela. Sendo assim, e uma vez que não seria possível conhecer todas aquelas pessoas que partilham de uma mesma identidade nacional, devemos ter uma ideia partilhada sobre aquilo que a constitui: "a diferença entre as diversas identidades nacionais reside, portanto, nas diferentes formas pelas quais elas são imaginadas" (Woodward, 2000, p. 24).
} 
um museu e maneiras mais dilatadas de se pensar, preservar e comunicar determinado patrimônio" (Azevedo \& Alfonsi, 2010, p. 279). O alargamento desta compreensão de patrimônio foi substancial para este contexto, uma vez que agora ele passa a incorporar as representações, práticas e expressões que caracterizam a cultura de cada povo. Suas festas, rituais, danças, ritmos e modos de fazer enraizados no cotidiano das comunidades adentram aos interesses museológicos (Arantes, 2004).

Amparadas com tecnologias de ponta, por meio de fotografias e textos verbais, tais exposições constituem-se como um novo modelo de comunicação para os museus ao promoverem novas significações na construção de discursos identitários e de valorização da memória. São narrativas biográficas que permitem interpretar diferentes conceitos. Neste cenário, o futebol e seus ídolos ganham espaço como fenômeno social amplo, que mobiliza, atravessa e costura diversas dimensões sociais, acionando ideais, identificações e sentimentos de pertencimento. No caso do Brasil, o futebol é um elemento que condensa questões caras para a constituição da brasilidade.

As primeiras décadas do século $X X$ foram de investimento de vários significados do que era e do que devia ser o Brasil. Tomada como forma nova de diferenciação nacional, a mestiçagem transformou-se em símbolo da brasilidade a partir do sincretismo de elementos culturais. O futebol, o samba, a capoeira e as religiões afro-brasileiras foram progressivamente constituindo-se em símbolos do Brasil e da brasilidade a partir dos anos de 1920. A noção de miscigenados emoldurou estes símbolos nacionais e dramatizou uma das marcas distintivas da identidade: a ilustração ideológica da propalada convivência pacífica entre as diferentes gentes e culturas que formaram o povo brasileiro, e que, apesar das diferenças sociais e culturais, viviam em "antagonismos equilibrados", para usarmos um conceito de Gilberto Freyre sobre a sociedade brasileira (Soares, 2003, p. 155).

Freyre (1933/1992) tomou a interpretação pessimista do Brasil, assolado pelas teorias racialistas do século XIX, que viam na miscigenação das raças a degeneração e o motivo do atraso da nação, e a transformou em esperança pelo encontro de raças e culturas que teria feito nascer civilização tropical e singular. Ele se tornou o "autor de não-ficção mais lido no Brasil porque foi capaz de tomar uma das questões que mais preocupavam a elite brasileira (...) e virá-la de ponta-cabeça" (Skidmore, 1994, p. 42).

Assim, diversas expressões culturais nativas, bem como a apropriação de elementos estrangeiros, aqui, eram transformadas em marcas da singularidade nacional na estrutura do pensamento freyreano. A análise da produção discursiva sobre o "ser brasileiro" passa pela compreensão do conteúdo simbólico e político da mestiçagem, que toma o futebol como um lugar de sua expressão e de construção da identidade nacional (Freyre, 1938). Sendo o futebol um dos elementos que expressava a permissibilidade das relações entre os brasileiros, logo assumiu, ao longo do século $X X$, a função simbólica da construção imaginária da nação que ganha vida, entre outros espaços, nos museus.

Nestes lugares da memória do futebol brasileiro, uma personagem nos chama atenção: Arthur Friedenreich, que ocupa na historiografia do futebol nacional um capítulo à parte. Em virtude do prestígio, adquirido pelo seu alto desempenho nas partidas de futebol do começo do século XX, pode ser tomado como o principal jogador do futebol 
brasileiro daquele período. Nos lugares de memória, os escritos e as imagens sobre ele dão destaque aos feitos da sua carreira futebolística, e sua excepcionalidade como jogador. Todavia, em conjunto com tais apontamentos, os museus também marcam a ambiguidade da identidade racial vivida por Friedenreich, o que em tese expressa uma das faces do "racismo à brasileira".

Um indício dessa ambiguidade pode ser observado a partir da participação de Friedenreich nos jogos "Preto x Branco" que ocorreram a cada 13 de maio de 1927 até 1939 em São Paulo (SP) para celebrar o dia comemorativo da abolição da escravatura (Abrahão \& Soares, 2009). Nas edições de 1927 e 1928, Friedenreich participou desses jogos comemorativos e atuou no time dos brancos, fato que talvez indique que ele, naquela sociedade, identificava-se e era aceite como tal. Noutra direção, Friedenreich aparece na memória de grande parte da produção acadêmica sobre a história do futebol brasileiro, incluam-se os museus da cidade de São Paulo, como mulato ou até mesmo negro. Wisnik (2008) adiciona o fato de ele ter sido também o capitão da equipe dos brancos nos jogos de "Preto x Branco", o que não impediu que participasse como jogador do time dos negros, em 1929, num combinado de equipes paulistas contra cariocas. Sobre esse episódio, Mário Rodrigues Filho (2003) o eleva à condição de herói e sugere que ele poderia escolher em qual equipe desejava jogar.

Friedenreich, subjetivamente e junto aos seus pares, reconhecia-se como branco e, provavelmente pelo prestígio acumulado, era tratado assim também naquela sociedade. O embranquecimento era forma de os mestiços serem integrados à boa sociedade (Nogueira, 1998). Sua ascendência negra, pelo lado da mãe, permitia que também fosse identificado como mestiço, o que permitiu que participasse num jogo entre os negros paulistas contra cariocas ${ }^{2}$. Segundo Wisnik (2008), apoiado numa interpretação de Ugo Giorgetti, ao que tudo indica, essa personagem sempre teria assumido uma posição ambivalente sobre a questão racial, interpretação bem plausível numa sociedade na qual o critério cromático impactava positiva ou negativamente nas relações e nas possibilidades sociais (Nogueira, 1998). Além disso, o ex-jogador se identificava pelo sobrenome alemão.

Aqui, a questão não é banalizar a discussão e simplesmente dizer se ele era branco, mulato ou preto, mas tomá-lo como um caso para pensar como a linha de cor, raça e classe, associada a outros indicadores culturais e econômicos, dramatiza a ambiguidade sobre o que é ser branco e ser preto no Brasil. Em alguma medida, o debate sobre a questão racial do Brasil auxilia-nos a entender a discrepância entre a autoidentificação como branco e a heteroidentificação como mestiço ou negro por grande parte da historiografia que se ocupou em compreender as relações raciais no universo do futebol brasileiro. No que diz respeito à escrita dessa história, às voltas com os mecanismos da identidade nacional, qual leitura podemos fazer sobre o futebol e o seu principal personagem das primeiras décadas do século XX? A fim de responder a esta questão, o objetivo deste artigo é analisar os escritos e as imagens sobre o ex-jogador Arthur Friedenreich em museus da cidade de São Paulo.

\footnotetext{
${ }^{2}$ Todavia, devemos observar que em nossos investimentos na busca de fontes e na própria literatura não encontramos vinculações de Friedenreich com o movimento negro da época.
} 
Para tanto, ocupamo-nos do conteúdo de três exposições de museus da cidade, duas são permanentes, no Museu do Futebol e no Museu na Federação Paulista de Futebol, e uma temporária, no Museu Afro-Brasil, que tratou da trajetória do negro no futebol e foi denominada "De Arthur Friedenreich a Edson Arantes do Nascimento: o negro no futebol brasileiro". A análise de tais escritos e imagens, em formatos fotográficos presentes nas exposições, parte da compreensão da fotografia como um instrumento que capta e eterniza determinado instante, que traz em si uma mensagem produzida por alguém. De acordo com Kossoy (2001), é testemunho da verdade do fato ou dos fatos, ganhando status de credibilidade. Sônego (2010), por sua vez, abordando o tema dos documentos imagéticos em pesquisas históricas, apoia-se em Pierre Bourdieu (1965) para afirmar que, no mundo moderno-contemporâneo, as fotografias refletem visualmente valores ideológicos, sistemas estéticos e éticos de grupos sociais. Sendo assim, a análise das imagens sobre Arthur Friedenreich levou em conta os dois sentidos que fazem parte tanto da fotografia, quanto do seu conteúdo.

Rodrigues (2007) apresenta tais sentidos, denominando-os de denotativo e conotativo. No primeiro, não há espaço para interpretações, a imagem é apenas uma cópia do conteúdo que objetivou apresentar. Já o sentido conotativo permite à imagem ser interpretada de diferentes maneiras, pois se reconhece sua característica polissêmica, ambígua por natureza. Logo, exploraram-se os sentidos denotativos e conotativos das imagens de Friedenreich na perspectiva de uma análise histórica, considerando que, segundo Rodrigues (2007), além do aspecto objetivo, o da fotografia em si, há um componente subjetivo que depende da vivência, da percepção e da sensibilidade dos autores das mesmas.

\section{Friedenreich nos museus de São Paulo}

Nossas fontes são as imagens ${ }^{3}$ e textos expostos nos museus visitados. A primeira encontra-se no Museu do Futebol, com uma exposição permanente sobre o futebol no Brasil, localizado no estádio do Pacaembu, São Paulo. No museu, como legenda da Figura 1 pode ser lido:

com os cabelos alisados, uma de suas marcas, Arthur Friedenreich, filho de mãe negra e pai alemão, é homenageado em jogo da seleção carioca de futebol, junto com Fausto, o Maravilha Negra - apelido ganho durante a Copa de 30, no Uruguai. (Legenda Figura 1, Museu do Futebol, São Paulo)

Embora o Museu do Futebol não indique a data da foto, ela provavelmente se refere ao jogo amistoso entre a equipe combinada Rio-São Paulo contra a seleção francesa, que teria acabado de participar na Copa do Mundo de 1930. O jogo teria sido realizado à noite, no estádio do Fluminense, no Rio de Janeiro, no dia 1 de agosto de 1930. O selecionado brasileiro venceu o certame.

\footnotetext{
3 Todas as fotografias trabalhadas no artigo foram capturadas pelo pesquisador Bruno Abrahão nos museus.
} 


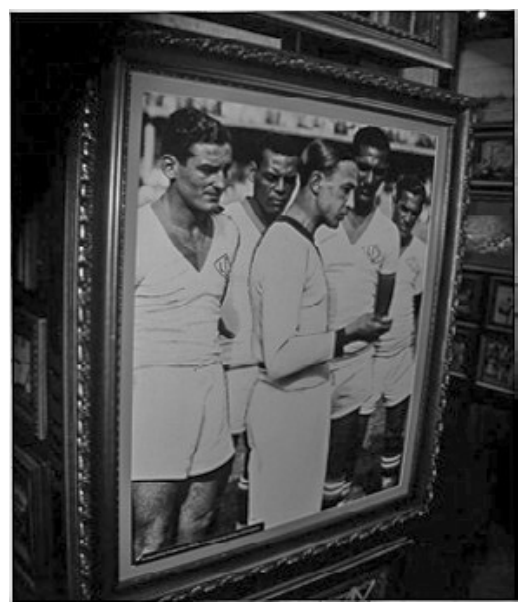

Figura 1: Amistoso combinado Rio-São Paulo contra seleção francesa

Fonte: Museu do Futebol

O texto fornece o indício de que a estética de Friedenreich é lida pelo museu e pela historiografia do futebol como uma forma de branqueamento (Nogueira, 1998). Mário Rodrigues Filho, conhecido como Mário Filho (1947/2003), ao publicar a primeira edição do livro O negro no foot-ball brasileiro em 1947, torna Friedenreich, entre outros negros e mulatos, não apenas o primeiro herói do futebol brasileiro, mas, sobretudo, como aquele que teria inaugurado a saga negra neste esporte e aberto as portas para sua democratização racial no país. Para Mário Filho, a vitória brasileira no campeonato sul-americano de 1919 seria uma inflexão do papel do negro no futebol, pois, "o chute de Friedenreich teria aberto o caminho para democratização do futebol brasileiro, democratização que viria lentamente, mas que não pararia mais, a despeito de tudo" (Filho, 1947/2003, p. 69). Apesar da leitura de Mário Filho sobre o papel de Friedenreich na história do futebol brasileiro, ele não deixa de assinalar que esse primeiro herói era mais um mulato que queria se passar por branco4 (Filho, 1947/2003).

Mário Filho (1947/2003) interpretou a estética produzida por Friedenreich como uma forma de branqueamento para esconder a associação entre mestiçagem e posição social, mas decidiu em sua narrativa marcar que ele era mulato para construir a trajetória positiva do papel democrático da cultura brasileira espelhada no seu futebol mestiço. Isso assinalaria a presença de pretos e mulatos incorporados ao esporte antes destinado às elites brancas. Observa-se que a legenda da Figura 1 marca elementos da estética corporal e da origem biológica de Friedenreich: os cabelos alisados, como indicador de embranquecimento, e sua origem mestiça. Esses indícios demonstram como o corpo, sua aparência e origens raciais compõem uma narrativa sobre Friedenreich e sobre a história do futebol brasileiro. Profundamente influenciada por Gilberto Freyres, a narrativa de Mário Filho indicava o espaço do futebol como mais um exemplo de integração nacional dos diferentes povos e raças que no Brasil aportaram (Soares, 2003).

\footnotetext{
${ }_{4}^{4}$ Sobre embranquecimento na sociedade brasileira, ver Nogueira (1998).

${ }^{5}$ Gilberto Freyre fez o prefácio da primeira edição de O negro no foot-ball brasileiro, em 1947.
} 
A contrapelo dessa posição, uma das denúncias realizadas pelo movimento negro é a das formas de opressão, de vergonha e de constrangimento que o ideal de branquitude foi impondo aos homens e às mulheres negras. Assim, o Museu do Futebol, ao destacar nas legendas a manipulação do cabelo realizada por Friedenreich, deixa ao observador uma pista sobre o dilema deste heroico personagem: alisar o cabelo era uma forma de afastar-se de um dos estigmas que associava a cor da pele mestiça ou preta às posições sociais inferiores. O cabelo liso seguramente era um dos marcadores de branquitude, portanto, de posição social e de beleza. A recorrência desse valor expressa os dilemas vividos por homens e mulheres afrodescendentes numa sociedade cujo status social passava (e ainda passa) pela linha de cor das pessoas (Almeida, 2019; Kowarick, 2003; Nascimento, 2016).

Em pesquisa nos microfilmes da Biblioteca Nacional do Rio de Janeiro, encontramos anúncios em periódicos que, inclinados para a causa negra em diferentes contextos, comercializavam produtos destinados à manipulação do cabelo, técnica que deve ser pensada como recurso de branqueamento. Entre os muitos encontrados, escolhemos, como exemplo, o jornal da imprensa negra O Clarim (Informe, 1935, p. 5), que publicou: "cabelos lisos? Allô... allô... Já alisou e ondulou seu cabelo, Amaral? Pois procure Pequita. Com o trabalho de Pequita o seu cabelo ficará - um amorzinho". A Imprensa Negra, um coletivo de jornalistas atuantes em São Paulo nas décadas iniciais do século XX, tinha como objetivo não apenas denunciar a opressão e a exclusão social sofrida pelos negros e negras, mas também valorizar os feitos e distinções de seu grupo de referência na sociedade brasileira. Além disso, divulgava produtos e serviços voltados aos ideais de beleza perseguidos pelos negros na época, mesmo que algumas das tecnologias de embelezamento estivessem associadas, direta ou indiretamente, a valores estéticos da branquitude. Tal questão, em tese, poderia não estar na agenda do movimento negro à época.

No Museu da Federação Paulista de Futebol, o centenário do jogador foi lembrado em texto de Rubens Ribeiro, jornalista aposentado, que, na oportunidade da visita, ainda trabalhava naquela instituição conforme a Figura 2 (ver Anexo 1).

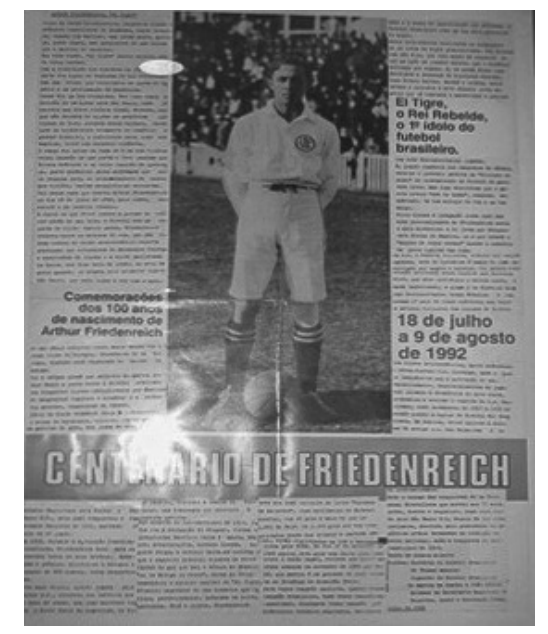

Figura 2: O jogador Friedenreich Fonte: Museu da Federação Paulista de Futebol 
Esta longa e rica matéria assinada pelo jornalista responsável no Museu da Federação Paulista de Futebol traz detalhes importantes da biografia de Friedenreich e dos clubes que ele defendeu. Os feitos da vitoriosa carreira e sua ambígua posição racial na sociedade brasileira, nem branco e nem preto, filho de branco alemão com negra brasileira, dão o tom do texto de Rubens Ribeiro (1996). Em relação à mãe de Friedenreich a matéria indica, pela primeira vez nas fontes consultadas, que seu nome era Matilde. Destacamos que, na trajetória do jogador, não são raras as passagens que recordam o nome do pai, Oscar, sobretudo pelo fato de acompanhar o sobrenome Friedenreich. A mãe descrita por Ribeiro (1996) como "uma jovem pobre, mestiça, quase negra ${ }^{6}$, mas possuidora de uma beleza que o cativou de imediato", observemos que o "mas" na frase indica que, apesar das origens social e racial, ela tinha atributos corporais que permitiram seu casamento e mobilidade com um homem branco. A mulata é um dos símbolos da identidade nacional que associa mestiçagem à singular e sensual beleza das mulheres mestiças, tais marcas identitárias podem ser vistas nas obras clássicas de Gilberto Freyre $^{7}$ e em músicos, cartunistas, artistas e poetas brasileiros ${ }^{8}$. 0 silêncio e o quase anonimato da mãe de Friedenreich na memória refletem os valores patriarcais da sociedade brasileira, os quais secundarizam o papel da mulher, localizam e a valorizam apenas em espaços específicos da vida privada. Outra dimensão do papel secundário da mulher deve-se ao fato de que o futebol é visto como um espaço do coito privado masculino, como sentenciaram Elias e Dunning (1992), apesar dos atuais avanços e da quebra de barreiras pelas mulheres neste esporte.

A matéria segue elencando outros pontos importantes da sua biografia como a condição socioeconômica da família, seu gosto inicial mais inclinado para a "rua" do que os campos aristocráticos da elite paulistana, cujo acesso the seria facilitado pelo sobrenome europeu, símbolo de distinção naquela sociedade. Isto possibilitava que ele transitasse entre esses dois mundos, o suficiente para trazer dúvidas, conforme as palavras do jornalista: "qual das duas personalidades de Friedenreich seria a mais autêntica: a do jovem que frequentava festas de família, ou a que levava o 'mulato de olhos verdes' a buscar o convívio da gente humilde das ruas" (Ribeiro, 1996). Rubens Ribeiro (1996) constrói retrospectivamente Friedenreich como um mediador de dois mundos, o da sociedade e o do futebol: "com ele o esporte elitista trazido dos campos ingleses teve que curvar-se à magia do jogo improvisado por negros e mulatos". Temos aqui na mestiçagem cultural,

\footnotetext{
${ }^{6}$ Observemos que o texto de Rubens Ribeiro (1996) revela, mesmo sendo laudatório, uma série de estigmas associados aos negros e mestiços no Brasil. Sobre o processo de rotulação e produção de estigmas ver Elias e Scotson (2000) e Erving Goffman (1963).

7 Freyre tratou em seus clássicos livros, Casa grande Q senzala (1933/1992) e Sobrados e mucambos (1936), o papel da mulher negra e da mulata na formação social brasileira.

${ }^{8}$ Poderíamos citar vários exemplos, mais apenas três bastam: Lanfranco Aldo Ricardo Vaselli Cortellini Rossi Rossini, chamado de Lan (1925), é um cartunista italiano radicado no Brasil que dedicou seus cartuns à figura da mulata; Di Cavalcanti (1897-1976), pintor brasileiro, eternizou as mulatas em suas telas; Dorival Caymmi, cantor e compositor brasileiro, também cantou as mulatas em suas canções; Moraes Moreira (1947-2020), músico e compositor, na canção "Meninas do Brasil" (Moreira, 1980, faixa 04) escreve quatro versos que explicitam o simbolismo da mulata: "três meninas do Brasil, três corações democratas/Tem moderna arquitetura ou simpatia mulata/ (....) Deus me faça brasileiro, criador e criatura/Um documento da raça pela graça da mistura/Do meu corpo em movimento, as três graças do Brasil/Têm a cor da formosura".
} 
no encontro entre classes e raças, a trilha deixada por Gilberto Freyre que se tornou uma interpretação popular para "dentro e fora do Brasil" (Skidmore, 1994, p. 32).

Em seu laudatório texto, Rubens Ribeiro (1996) refere a contribuição de Friedenreich à estética do futebol brasileiro, os clubes que defendeu, detalhes do seu apelido, sua presença no livro dos recordes como o maior artilheiro do futebol mundial com 1329 gols, até sua morte pobre, esquecida e vista como pouco condizente com a condição do primeiro herói nacional no futebol. Ele alcançou a conquista inédita do sul-americano em 1919, quando foi o autor do gol daquela vitória, aos três minutos da segunda prorrogação, após empate em zero a zero no tempo normal e na primeira prorrogação.

As fotos a seguir foram expostas no Museu Afro-Brasil, em julho de 2010, em exposição nomeada "De Arthur Friedenreich a Edson Arantes do Nascimento: o Negro no futebol brasileiro". A mostra destacou a presença de jogadores negros na história do futebol no Brasil como elemento central da formação da identidade nacional e foi inspirada no livro $O$ negro no futebol brasileiro, que teve primeira edição em 1947 e a segunda ampliada em 1964 (Filho, 1947/2003). Como o livro destaca o processo de conquista desse espaço social pelo negro, Friedenreich representaria o primeiro herói do futebol brasileiro e Pelé, o herói definitivo, aquele que provaria o definitivo processo de democratização do futebol no Brasil (Soares, 1999).

A figura de Friedenreich no gol da vitória do sul-americano de 1919, mais que o próprio gol, teria produzido a eficácia simbólica, demonstrando que o futebol se tornou, naquele momento, espaço da expressão da democracia racial no Brasil. A popularidade de Friedenreich mostrava que a exclusividade do branco no futebol estava chegando ao fim. Mário Filho também quer demarcar que a democratização do futebol se iniciou no momento em que este esporte se tornou um lugar de expressão do mérito para além das origens sociais e étnicas. O que importava era a vitória, a bola lá dentro, no fundo das redes: "metida por um branco, um mulato, um preto. Pouco importava" (Filho, 1947/2003, p. 112). Destaque-se que esse livro marcou e balizou boa parte da literatura sociológica e histórica sobre o futebol no Brasil (Soares, 1999) e também os museus que tratam desta temática. Todavia, no Museu Afro-Brasil fica clara a intenção de demonstrar o papel fundamental que o negro teve nas glórias alcançadas pelo futebol brasileiro no mundo.

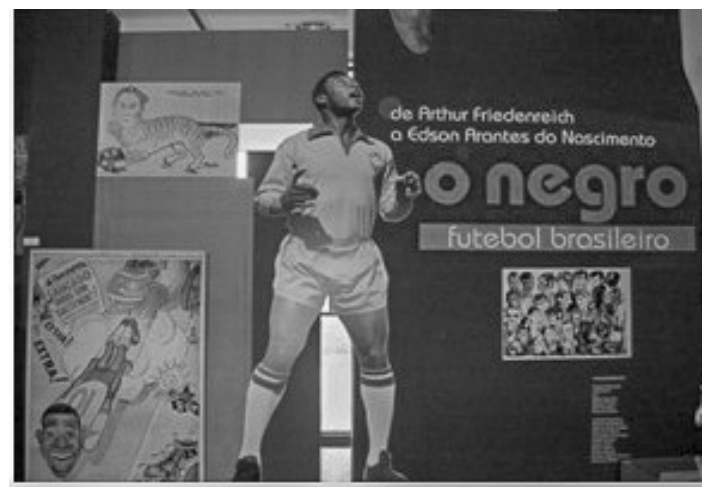

Figura 3: O negro no futebol brasileiro

Fonte: Arquivo de Emanoel Araújo, Museu Afro-Brasil 
A fotografia seguinte foi ampliada e ocupava sozinha uma grande parede, como um painel, na exposição do Museu Afro-Brasil.

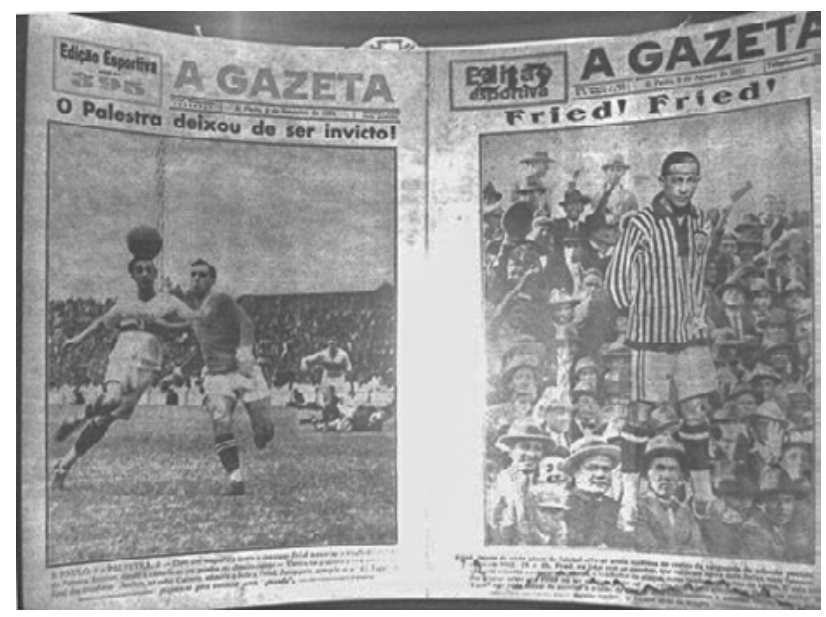

Figura 4: Fried! Fried!

Fonte: Arquivo de Emanoel Araújo, Museu Afro-Brasil

A imagem direita da Figura 4 apresenta a página de $A$ Gazeta de 9 de agosto de 1931 e a manchete exclama o nome de Fried. Nela, podemos observar o jogador colocado como uma figura que "paira no ar" com o fundo de espectadores. O texto abaixo da página do jornal apresenta a seguinte legenda:

Fried, depois de vinte annos de futebol official, ainda continua no centro da vanguarda do futebol da selecção. Hoje, como em 22, 23 e 25, Fried, irá lidar com os gaúchos, que voltaram agora mais fortes, mais famosos. E não será somente o consagrado mestre, o conductor do ataque, como também o capitão da turma. É esta uma das poucas vezes que Fried irá ser o capitão, posto este que elle nunca teve simpathias. Desta vez, porém, "El Tigre" não pôde deixar de acceitar a missão de chefiar seus companheiros e estamos certos, saberá ser o mesmo mestre, mesmo ídolo de sempre. (Fried! Fried!, 1931, p. 1)

Na imagem à esquerda da Figura 4, de A Gazeta de 3 setembro de 1934, a chamada destaca que "o Palestra deixou de ser invicto". O gol que teria quebrado a invencibilidade do Palmeiras foi marcado por Friedenreich. Embaixo da foto, lê-se:

com um magnífico tento Fried arrancou o título de campeão invicto do $\mathrm{Pa}$ lestra, hontem, dando a victoria ao seu quadro no clássico cotejo - Vemos na gravura acima uma acção final dos tricolores. Araken, ao cahir cernera e adeanta a bola a Fried. Junqueira antepõe-se a "El Tigre" e prepara-se para executar a puxada. (O Palestra deixou de ser invicto, 1934, p. 1)

Friedenreich teria se tornado "El Tigre" por sua atuação impecável no campeonato sul-americano de 1919, atual Copa América, e o epíteto foi lhe dado pela imprensa 
uruguaia, impressionada com a qualidade técnica do jogador. No museu, o banner representado pela Figura 5 indicava esse epíteto que a imprensa passou a usar para referir-se às proezas de Friedenreich no campo.

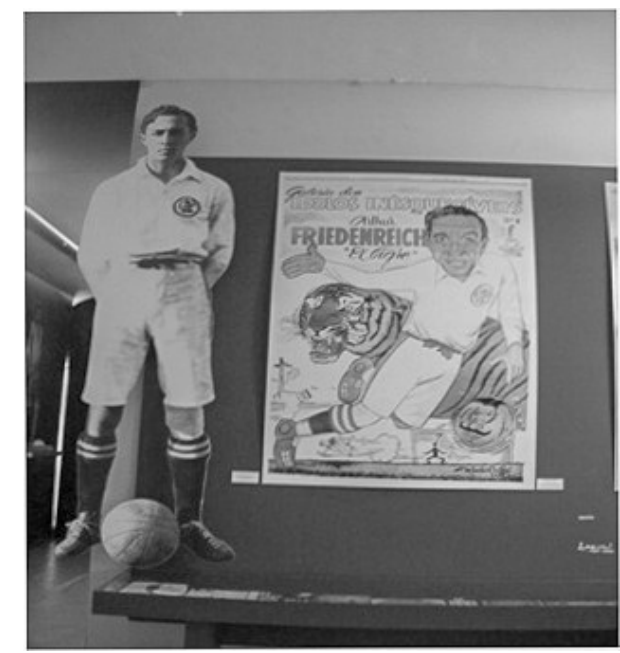

Figura 5: As proezas de Friedenreich

Fonte: Arquivo de Emanoel Araújo, Museu Afro-Brasil

Tanto as fotografias dos jornais montadas em forma de painel, quanto esse banner, que reproduzia uma charge da época do "El Tigre", tinham por função rememorar os feitos de um herói do futebol brasileiro que deveria ser motivo de orgulho para os afrodescendentes e para os brasileiros em geral. Observe-se que esse tipo de exposição, no referido museu, tem a intenção objetiva de heroificar os personagens afrodescendentes, uma posição legítima numa sociedade cujo racismo é estrutural e ainda tem dificuldades de reconhecer a permanência da cultura escravocrata nas relações sociais (Souza, 2019).

O curador da exposição, Emanoel Araújo, apropriou-se da obra de Mário Filho no mesmo sentido de heteroidentificação dos jogadores negros, todavia, num tempo social e numa instituição na qual o efeito desejado de significação passa necessariamente pelas demandas de visibilidade e reconhecimento dos afrodescendentes na sociedade brasileira. Com sua obra, Mário Filho (2003) marcou a incorporação dos negros e a democratização do futebol, no sentido da democracia racial de Gilberto Freyre (Soares, 1999, 2003). A exposição no Museu Afro-Brasil, ao resgatar o tema e a obra de Mário Filho, realizou apropriações e leituras para destacar o papel do negro no futebol na construção da identidade nacional e para trazer questões e demandas contemporâneas do movimento negro, tais como a denúncia do racismo e a valorização da negritude com sua história de heróis nacionais. Na saída da exposição havia uma mensagem assinada por Emanoel Araújo que, além de curador da exposição, era também diretor do museu (Anexo 2).

Contextualizando a exposição, o texto de Emanoel Araújo retomava as origens do esporte na China, na Europa do século XIX e o seu desembarque no Brasil, com Charles Miller. Também reproduzia um discurso oficial e essencialista que torna o futebol quase uma dimensão natural da existência humana quando o remete à Ásia da antiguidade. 
Charles Miller seria o introdutor e o representante do futebol da e para as elites econômicas e culturais no Brasil. Entretanto, esse esporte não ficou restrito a esse grupo de status, pois foi apropriado pelas classes populares e pelos negros nos centros urbanos brasileiros do início do século XX. As origens do futebol que Emanoel Araújo descreve em poucas linhas é a história popularmente difundida, o que contraria boa parte da historiografia atual sobre a difusão do futebol no Brasil (Jesus, 1998).

Emanoel Araújo reproduz a equação de Mário Filho: o futebol, quando branco, era inglês e da elite, quando preto e miscigenado, era do povo e se tornou brasileiro (Soares, 1999). Ele chama a atenção para o processo de transformação social do futebol no Brasil por envolver grandes parcelas da população (negros, pobres e mestiços), pela sua dimensão lúdica no extravasamento das emoções e pelo seu potencial de promover pelo mérito pessoal a inclusão social. Embora reconheça estudos acadêmicos que se debruçaram sobre o futebol, o texto de Emanoel destaca uma lacuna acadêmica, identificada pelo diretor-curador do museu, no que diz respeito ao ingresso de negros e mestiços aos clubes elitistas do futebol brasileiro. Ele recorre ao prefácio de Gilberto Freyre em $O$ negro do futebol brasileiro (Filho, 1947/2003), para encontrar, no negro e na alma mestiça da cultura brasileira, o elemento que singularizou o futebol no país e lhe conferiu identidade.

A obra de Mário Filho data o período, por exemplo, quando Gilberto Freyre elaborou, como já dito, uma reinterpretação otimista do caráter nacional, superando o pessimismo ao atribuir um sentido positivo ao debate da miscigenação no Brasil (Skidmore, 1976, 1994). A ideologia da miscigenação valorizou a fusão das raças e das culturas que deu origem ao povo brasileiro. Com a ideia de síntese, da mistura e do encontro cultural, chegou-se à definição da identidade nacional, daquilo que caracterizaria o "ser brasileiro", definição essa que se expressaria em diferentes práticas sociais, entre elas, o futebol. Assim, a exposição repassa a mensagem de que quando o futebol incorporou negros, mestiços e brancos pobres aos seus quadros, ele se transformou em metonímia do caráter nacional (Franzini, 2003).

João Lyra Filho (1973), ao produzir uma das obras germinais sobre a Sociologia do Esporte no Brasil seguiu essa tradição. O negro, com a qualidade de seu futebol, teria provocado a democratização desse espaço social, antes destinado aos jovens brancos e administrado por "certos dirigentes desportivos ciosos de sua cor, sua roupa de tecido importado e sua posição social" (Lyra Filho, 1973, p. 81). O mercado competitivo do futebol obrigou, mesmo a contragosto de parte da elite dirigente, a incorporação de negros e mulatos, selecionados no seio do povo-massa, aos clubes de elite. Lyra Filho (1973) sugere que a democratização e a apropriação desse esporte se deu porque "o futebol pegou no Brasil e aqui se tem valorizado exponencialmente graças, em grande parte, aos negros e aos mulatos. Suponho que esta verdade não pode ser contradita; os fatos valem por si" (p. 89). Lyra Filho argumenta que o futebol, quando restrito aos círculos da elite branca, era apenas uma moda estrangeira, quando incorpora negros e mulatos, o esporte cai no gosto popular e se torna brasileiro (Soares, 1999). De fato, as leituras de Gilberto Freyre e de Mário Filho sobre o papel do futebol na formação social brasileira se tornaram hegemônicas até os anos de 1990, tanto no jornalismo quanto nas Ciências Sociais (Soares, 1999). 
O rememorar Friedenreich e outros grandes jogadores negros pela coleção apresentada nesta exposição, para além da virtuose dos jogadores, objetivava um tipo de comunicação que intenciona afetar as subjetividades dos frequentadores - subjetividade que deve ser confrontada com os dilemas da raça e do racismo em nossa sociedade. Uma das formas de racismo é o apagamento ou a invisibilidade do papel do negro na construção nacional; portanto, a exposição, objetivamente, deu visibilidade à virtuose do homem negro no desenvolvimento do vitorioso futebol brasileiro. Mas, Emanoel Araújo, sem perder a dimensão crítica, encerra o texto da exposição destacando as manifestações de injúrias racistas ainda presentes no futebol de hoje e questiona se o futebol "seria mesmo" expressão e acesso à cultura brasileira e um espaço de "ascensão do esportista negro". O curador aqui se reportava ao fato de jogadores negros terem sido chamados de macacos em diferentes audiências no mundo (Abrahão \& Soares, 2011). Observe-se que o museu, ao tomar o futebol e os grandes jogadores afrodescendentes, optou por conciliar a visão tanto de luta, integração e heroificação do negro no futebol, e por provocar a crítica ao racismo ainda presente no futebol e na sociedade.

\section{ConclusÃo}

Quais significados Friedenreich assume em museus da cidade de São Paulo que tematizaram sua biografia? Fazendo uma síntese, ele aparece nesses lugares de memória como um símbolo do sucesso do futebol mestiço, da mobilidade nesse espaço social e como uma personagem que marca as tensões raciais e os processos de embranquecimento. Sua identificação racial no presente e sua alta competência futebolística no passado tornam-o um símbolo apropriado pela memória social nas exposições sobre o futebol brasileiro. Para as exposições em seu conjunto, Friedenreich simboliza tanto a crítica às suas supostas estratégias de embranquecimento, quanto à identificação de um herói negro que dignificou o grupo étnico e construiu a saga do futebol brasileiro.

A ambiguidade em torno de sua identificação racial o transformou num dos símbolos do futebol brasileiro e num dos heróis negros que invadiram este espaço pela competência e mérito, contribuindo para a democratização do futebol, mas também revela a especificidade da discriminação e do racismo no país. A biografia de Friedenreich dialoga com as características do "preconceito à brasileira" interpretado, entre outros estudiosos, por Oracy Nogueira (1998) como "preconceito de marca" (p. 170). Diferentemente do preconceito racial e irredutível ao preconceito de classe, a especificidade do preconceito que se desenvolveu no Brasil atingiria até mesmo pessoas negras e pardas das camadas superiores, como parece ser o caso do ex-jogador.

No Brasil, diz Nogueira (1998), os indivíduos são classificados e se classificam a si próprios como brancos, pardos ou mulatos claros, pardos ou mulatos escuros e pretos, levando em consideração a ausência ou a concentração de traços negroides (densidade da pigmentação, textura e cor dos cabelos, formato do nariz e dos lábios etc.), ou seja, a aparência resultante da combinação ou fusão de traços europeus e africanos. Consequentemente, o status ou o sucesso do indivíduo negroide dependeria, em grande parte, 
da compensação e da neutralização de seus traços - ou de seu agravamento "pela associação com outras condições, inatas ou adquiridas, socialmente tidas como de valor positivo ou negativo - grau de instrução, ocupação, aspecto estético, trato pessoal, dom artístico, traços de caráter etc." (Nogueira, 1998, p. 200).

Neste caso, se o alisamento dos cabelos, a frequência de clubes da aristocracia paulistana e o sobrenome do pai parecem ter neutralizado uma suposta marca da ancestralidade negra, representada pelo cabelo crespo, a origem popular da mãe e sua iniciação ao futebol nos campos dos terrenos baldios (chamados de várzea, no Brasil) da capital paulistana, Friedenreich, por certo, soube embranquecer para ter um lugar de destaque naquele espaço social destinado às classes altas da sociedade, seja por suas estratégias sociais e, principalmente, por seus inigualáveis méritos esportivos. Recorrentemente rememorado pelos museus que guardam a memória do futebol brasileiro, a biografia de Friedenreich chama atenção para o orgulho étnico e nacional investido na construção do primeiro grande ídolo deste esporte, ao mesmo tempo em que revela as ambiguidades da identificação racial no Brasil.

\section{REFERÊNCIAS}

Abrahão, B. O. D. L. \& Soares, A. J. G. (2009). O elogio ao negro no espaço do futebol: entre a integração pós-escravidão e a manutenção das hierarquias sociais. Revista Brasileira de Ciências do Esporte, 30(2), 9-23.

Abrahão, B.O. D. L. \& Soares, A. J. G. (2011). O corpo negro e os preconceitos impregnados na cultura: uma análise dos estereótipos raciais presentes na sociedade brasileira a partir do futebol. Movimento, 17(4), 265-280. https://doi.org/10.22456/1982-8918.20590

Almeida, S. (2019). Racismo estrutural (feminismos plurais). Belo Horizonte: Pólen Livros.

Andreoni, R. (2011). Museu, memória e poder. Em Questão, 17(2), 167-179. Retirado de https://seer.ufrgs.br/ EmQuestao/article/view/22251/14319

Arantes, A. (2004). O patrimônio imaterial e a sustentabilidade de sua salvaguarda. Resgate: Revista Interdisciplinar de Cultura, 12(1), 11-18. https://doi.org/10.20396/resgate.v12i13.8645608

Azevedo, C. \& Alfonsi, D. (2010). A patrimonialização do futebol: notas sobre o Museu do Futebol. Revista de História, (163), 275-292. https://doi.org/10.11606/issn.2316-9141.voi163p275-292

Bourdieu, P. (1965). Um art moyen: essai sur les usages sociaux de la photographie. Paris: Les Editions du Minuit.

Elias, N. \& Dunning, E. (1992). A busca da excitação. Lisboa: DIFEL.

Elias, N. \& Scotson, J. L. (2000). Os estabelecidos e os outsiders. Rio de Janeiro: Jorge Zahar Editor.

Filho, M. R. (1947/2003). O negro no futebol brasileiro. Rio de Janeiro: Mauad.

Fried! Fried! (1931, o9 de agosto). A Gazeta, p. 1.

Freyre, G. (1933/1992). Casa-grande a senzala: formação da família brasileira sob o regime da economia patriarcal. Rio de Janeiro: Record. 
Freyre, G. (1936). Sobrados e mucambos: decadência do patriarcado rural do Brasil. São Paulo: Companhia Editora Nacional.

Freyre, G. (1938, 17 de junho). Foot-ball mulato. Diários Associados. Retirado de https://comunicacaoeesporte. files.wordpress.com/2010/10/foot-ball-mulato-gilberto_freyre.pdf

Franzini, F. (2003). Corações na ponta da chuteira: capítulos iniciais da história do futebol brasileiro (1919-1938). Rio de Janeiro: DP\&A Editora.

Informe CA (1935). O Clarim da Alvorada, n. 4, p. 5.

Goffman, E. (1963). Stigma: notes on the management of spoiled identity. Nova lorque: Simon \& Schuster.

Jesus, G. M. (1998). Futebol e modernidade no Brasil: a geografia histórica de uma inovação. Lecturas: Educación Física y Deportes, 3(10). Retirado de https://www.efdeportes.com/efdı/geo.htm

Kossoy, B. (2001). Fotografia e história. São Paulo: Ateliê Editorial.

Kowarick, L. (2003). Sobre a vulnerabilidade socioeconômica e civil: Estados Unidos, França e Brasil. Revista Brasileira de Ciências Sociais, 18(51), 61-86. https://doi.org/10.1590/S0102-69092003000100006

Lyra Filho, J. (1973). Introdução à Sociologia dos Desportos. Rio de Janeiro: Bloch Editores.

Moreira, M. (1980). Meninas do Brasil. In Bazar Brasileiro [CD]. São Paulo: Marco Mazzola.

Nascimento, A. (2016). O genocídio do negro brasileiro: processo de um racismo mascarado. São Paulo: Perspectivas.

Nogueira, O. (1998). Preconceito de marca: as relações raciais em Itapetininga. São Paulo: Editora da Universidade de São Paulo.

Nora, P. (1993). Entre memória e história: a problemática dos lugares. Projeto História: Revista do Programa de Estudos Pós-Graduados de História, 10, 7-28.

O Palestra deixou de ser invicto (1934, 03 de setembro). A Gazeta, p. 1.

Rodrigues, R. C. (2007). Análise e tematização da imagem fotográfica. Ciência da Informação, 36(3), 67-76. https://doi.org/10.1590/S0100-19652007000300008

Skidmore, T. (1976). O preto no branco: raça e nacionalidade no pensamento brasileiro. Rio de Janeiro: Paz e Terra.

Skidmore, T. (1994). O Brasil visto de fora. Rio de Janeiro: Paz e Terra.

Soares, A. J. (1999). História e a invenção das tradições. Revista Estudos Históricos, 13(23), 119-146. Retirado de http://bibliotecadigital.fgv.br/ojs/index.php/reh/article/view/2087

Soares, A. J. (2003). Futebol brasileiro e sociedade: a interpretação culturalista de Gilberto Freyre. In P. Alabarces (Ed.), Futbologías: fútbol, identidad y violencia en_América Latina (pp. 145-162). Buenos Aires: Clacso. Retirado de http://biblioteca.clacso.edu.ar/clacso/gt/20100920010258/9PII-Soares.pdf

Sônego, M. J. F. (2010). A fotografia como fonte histórica. Historiøe, 1(2), 113-120. Retirado de https:// periodicos.furg.br/hist/article/view/2366

Souza, J. (2019). A elite do atraso: da escravidão à Bolsonaro. Rio de Janeiro: Estação Brasil.

Wisnik, J. M. (2008). Veneno remédio: o futebol e o Brasil. São Paulo: Companhia das Letras. 
Woodward, K. (2000). Identidade e diferença: uma introdução teórica e conceitual. In T. T. Silva (Ed.), Identidade e diferença: a perspectiva dos estudos culturais (pp. 7-72). Petrópolis: Vozes.

\section{Anexos}

\section{Anexo 1: Rubens Ribeiro, julho de 1996 (Museu da Federação Paulista de} FUTEBOL)

\section{“Arthur Friedenreich, 'El Tigre'}

Filho de Oscar Friedenreich, imigrante alemão e próspero comerciante de Blumenau, Santa Catarina, casado com Matilde, uma jovem pobre, mestiça, quase negra, mas possuidora de uma beleza que o cativou de imediato.

Por essa razão, 'El Tigre' nasceu mulato, mas de olhos verdes. Com a libertação dos escravos, em 1888, a maior parte dos donos de fazendas do Sul atravessaram uma crise, que resultaria na queda do Império e na proclamação da República.

Oscar foi um dos atingidos. Por isso tomou a decisão de se mudar para São Paulo, onde já existia uma forte colônia alemã, fechada, mas que não deixava de ajudar os patrícios que vinham de fora. Através dessa colônia, Oscar pôde se estabelecer novamente no comércio e ganhar dinheiro, o suficiente para, com sua família, viver com relativo conforto.

O casal foi morar no $n^{\circ} 8$ da rua Victória, velho casarão de uma porta e três janelas que ficava defronte a um velho lampião de querosene, ponto preferido dos notívagos que ali se reuniam para, ao acompanhamento de chorosos violões, cantar melancólicas serenatas.

Foi nessa casa que nasceu Arthur Friedenreich no dia 18 de julho de 1892, meio claro e meio escuro, de cabelos crespos.

À época em que Friedenreich começou a gostar de correr atrás de uma bola, o futebol era um esporte de elite. Garoto pobre, Friedenreich cresceu entre os meninos de rua, que não tinham acesso ao aristocrático esporte praticado pelos estudantes do Mackenzie College e associados de clubes - a elite paulistana da época. Aos doze anos de idade no meio de gente grande, já atuava pelo primeiro time do São Paulo, que nada tinha a ver com o São Paulo Athlétic Club, muito menos com o atual clube do Morumbi. Tratava-se de um timinho, fundado pela rapaziada do bairro do Bexiga.

Foi a origem alemã que permitiu ao garoto Arthur fazer a ponte entre o futebol praticado nos elegantes clubes freqüentados por famílias de imigrantes ingleses e alemães - e as peladas dos meninos, organizadas na várzea.

Sócio do Clube Germânia (hoje E. C. Pinheiros) e aluno do Mackenzie, cultivou com os garotos do povo, nos jogos de rua, a habilidade e o senso de improvisação que marcaram o futebol brasileiro como um dos mais criativos do mundo.

Esses antecedentes resultaram no surgimento de um jovem de dupla personalidade. Seu futebol era tão fino, que todo mundo se esquecia de ver em ação um jogador mulato que o Germânia aceitara por engano. E, da mesma forma que festejava a presença de distintos atletas, como Rubem Salles, Barthô e outros, batia palmas e aplaudia a arte daquele jovem magriço que começava a admirar o público com suas desconcertantes jogadas. 
E, quando aparecia nos campinhos de várzea, dava-se o inverso: parecia como um 'filhinho de papai' se intrometendo no futebol de garoto pobre. Mas logo descobriram que o garoto Arthur 'era da turma', simples, desafetado. Um bom moleque de rua e um bom amigo.

Ficou apenas a indagação sobre qual das duas personalidades de Friedenreich seria a mais autêntica: a do jovem que freqüentava festas de família, ou a que levava o 'mulato de olhos verdes' a buscar o convívio da gente humilde das ruas.

Com ele o esporte elitista trazido dos campos ingleses teve de curvar-se à magia do jogo improvisado por negros e mulatos. Foi grande a revolução provocada nesse esporte por Friedenreich, que nele introduziu o drible curto, o passe improvisado, a ginga e os floreios de um jogo desconcertante. Mesmo franzino e com 17 anos de idade enfrentou sem temor os métodos violentos das equipes de futebol dos clubes aristocráticos, agora defendendo o recém fundado $C$. A. I piranga, para o qual se transferiu sem a aprovação do pai.

Posteriormente, desentendimentos do jogador, aliados à decadência do novo clube, levaram-no a aceitar o convite do C. A. Paulistano, onde permaneceu de 1917 a 1930 só saindo quando a equipe de futebol foi desativada. Em seguida, Fried reuniu-se a atletas da antiga A. A. das Palmeiras e do próprio Paulistano para fundar o São Paulo F. C., pelo qual conquistou o Campeonato Paulista de 1931, marcando 32 gols em 25 jogos.

Em 1932, durante a Revolução Constitucionalista, Friedenreich doou para os rebeldes todos os seus troféus, medalhas e prêmios. Alistou-se e assumiu o comando de 800 homens, todos desportistas.

Três anos depois, quando jogava pelo Santos F. C., encerrou sua carreira aos 43 anos de idade, num jogo amistoso contra o River Plate da Argentina, no Rio de Janeiro, vestindo a camisa do Flamengo, em homenagem à torcida carioca.

Por ocasião do Sul-Americano de 1919, juntos com a delegação do Uruguai, vieram os jornalistas Maurício do Valle d’Amico, Eduardo Arrachavaleta, Lorenzo Sienra, Augusto Borges e Antonio Batista. Ao ouvirem o que o Zibecchi dissera de Fried (autor do gol que deu o título ao Brasil) 'ni la fatiga lo vence', deram ao ídolo brasileiro o apelido imortal de 'El Tigre'. Primeiro imperador de uma dinastia que incluiu, posteriormente, Leônidas da Silva, Garrincha, Pelé e outros, Friedenreich teve seu nome incluído no livro 'Guiness de Recordes', como artilheiro do futebol mundial, com 46 gols a mais que os 1283 gols de Pelé.

Os 1329 gols por ele conquistados desde a sua primeira partida estão registrados pela CBF e reconhecidos pela FIFA. No dia 16 de setembro de 1928 marcou sete gols em um único jogo (9 a o sobre o União Lapa), recorde que seria quebrado somente em novembro de 1964 por Pelé, que marcou 8 na goleada de 11 x o imposta ao Botafogo de Ribeirão Preto.

Sete vezes campeão paulista, quatro vezes campeão brasileiro, duas vezes campeão sul-americano, dezessete vezes campeão por diferentes torneios regionais, nacionais ou internacionais.

Este é o resumo das conquistas de um fenomenal futebolista que morreu aos 77 anos, pobre, doente e esquecido, numa casa doada pelo São Paulo F. C., depois de ter 
sido, inclusive, recebido pelo presidente da República Arthur Bernardes na condição de herói nacional, após a conquista do Sul-Americano de 1919".

\section{Anexo 2: Emanofl Araújo, Curador Diretor (Musfu Afro-Brasit)}

"O futebol teve suas origens na China. Atravessou o Atlântico ainda no século XIX e chegou até nós através dos ingleses na figura de Charles Miller e foi primeiramente introduzido nas chamadas classes alta e média da sociedade emergente do século passado e nos clubes esportivos e sociais da elite paulista, e creio que assim foi no Rio de Janeiro em todos os outros estados brasileiros que descobriram o sucesso dessa modalidade esportiva e o quanto ela tocava a alma latina dos sul americanos.

Muitos trabalhos e teses foram escritos sobre o futebol no Brasil. Analisados sobre diferentes aspetos, desde os antropológicos, sociológicos, etnológicos, cronistas, jornalistas, poetas, escritores, curiosos, apaixonados e seduzidos pelo futebol o único esporte que une dança, uma espécie de domínio do corpo e de muitos gingados, equilibristas do espaço onde a magia está em dominar uma bola que às vezes tem caprichos próprios de um ser vivo, capaz de transformar sua magia em momentos de sucesso ou do mais puro e terrível fracasso.

O fato é que o futebol, que há muito virou paixão nacional, será sempre motivo de transformações sociais de quem na prática esportiva ascende e trasncende pelo talento e pelas qualidades ímpares de um grande atleta.

O futebol assim como o carnaval e outras manifestações populares no Brasil, ocupa grandes espaços na mídia por se tratar da capacidade de envolvimento com as mais diferentes camadas da sociedade brasileira, pelo grande elán lúdico contido nessa forma de extravasar as frustações das conquistas sociais de um povo que necessita desses escapes enquanto espera uma grande inclusão social que the adote como cidadão de fato.

A Academia por vezes tem se ocupado desse grande palco de inclusão social e desse frenesi de intermináveis paixões. Contudo são pálidas as contribuições para se estudar o ingresso dos negros e mestiços nos chamados esportes de elite, muito embora essas mudanças tenham suas prórpias regras.

Gilberto Freyre, o autor de Casa Grande e Senzala, comenta no prefácio do livro Negro no Futebol de Mário Filho:

Mário Filho nos põe diante do conflito entre estas duas forças imensas - a racionalidade e a irracionalidade - no comportamento ou na vida dos homens. No caso, homens do Brasil. Homens de uma sociedade híbrida, mestiça, cheia de raízes ameríndias e africanas e não apenas européias. Sublimando tanto do que é mais primitivo, mais jovem, mais elementar, em nossa cultura, era natural que o foot-ball, no Brasil ao engrandecer-se em instituição nacional, engradecesse também o negro, o descendente de negro, o mulato, o cafuzo, o mestiço.

Claro que o futebol como manifestação nacional, expõe a verdadeira face do país, com seus preconceitos agora vistos até nas manifestações das torcidas e internamente entre os próprios jogadores de diferentes clubes. 
O futebol seria mesmo cultura brasileira?

Seria uma porta de entrada à cultura brasileira?

Poderia ser uma porta de entrada para ascensão social do esportista negro?".

\section{NOTAS BIOGRÁFICAS}

Bruno Abrahão é doutor (2010) em Educação Física pela Universidade Gama Filho. É Professor Adjunto do Fepartamento de Educação Física, Faculdade de Educação, Universidade Federal da Bahia (UFBA). Leciona e orienta no Programa de Pós-Graduação em Educação da UFBA na linha de pesquisa Lazer, Cultura Corporal e Educação. É um dos coordenadores do grupo de pesquisa CORPO Cotidiano Resgate Pesquisa e Orientação da UFBA.

ORCID: https://orcid.org/0000-0003-0155-8500

Email: bruno.abrahao@ufba.br

Morada: Av. Reitor Miguel Calmon, s/n - Vale do Canela, Salvador - BA, 40110-100

Francisco Caldas é professor do Instituto Federal de Educação, Ciência e Tecnologia do Sertão Pernambucano, é mestre em Educação Física pela Universidade Federal do Vale do São Francisco (UNIVASF). Doutorando do Programa de Pós-Graduação em Educação da Universidade Federal da Bahia (UFBA). É membro do grupo de pesquisa CORPO Cotidiano Resgate Pesquisa e Orientação da UFBA.

ORCID: https://orcid.org/0000-0001-5542-2436

Email: demetriuscaldas@hotmail.com

Morada: Rua $43 n^{\circ}$ 50, Jatobá, Petrolina-PE - Brasil

Antonio Soares é Professor Titular da Faculdade de Educação da Universidade Federal do Rio de Janeiro (UFRJ); professor do Programa de Pós-graduação em Educação da UFR); Pesquisador Produtividade CNPq-1D; Cientista do Nosso Estado -FAPER.

ORCID: https://orcid.org/0000-0001-7769-9268

Email: antoniojsoares@pq.cnpq.br

Morada: Av. Paster, 250 - Urca - Rio de Janeiro - Campus da Praia Vermelha - Faculdade de Educação

Submetido: $20 / 05 / 2020$

Aceite: 06/06/2020 